\title{
Essais
}

Revue interdisciplinaire d'Humanités

\section{Le musée comme trace historique entre science et politique}

Le cas de la transformation des musées de la Nation en Musées de l'Europe

\section{Camille Mazé}

\section{OpenEdition}

\section{Journals}

Édition électronique

URL : http://journals.openedition.org/essais/5587

DOI : 10.4000/essais.5587

ISSN : 2276-0970

Éditeur

École doctorale Montaigne Humanités

Édition imprimée

Date de publication : 15 janvier 2015

Pagination : 38-55

ISBN : 978-2-9544269-4-5

ISSN : $2417-4211$

Référence électronique

Camille Mazé, "Le musée comme trace historique entre science et politique », Essais [En ligne], 6 |

2015, mis en ligne le 30 novembre 2020, consulté le 02 décembre 2020. URL : http://

journals.openedition.org/essais/5587; DOl : https://doi.org/10.4000/essais.5587 


\section{Le musée comme trace historique entre science et politique. Le cas de la transformation des musées de la Nation en Musées de l'Europe}

\section{Camille Mazé}

Les musées de société ${ }^{1}$ peuvent être considérés comme un sismographe privilégié des rapports à "l'identité ", au passé (à l'histoire et à la mémoire) et au territoire d'une société donnée à un moment donné. Ainsi, qu'il s'agisse des musées d'ethnologie ou d'anthropologie, des musées de culture ou de civilisation, des musées d'histoire, des historiaux ou des mémoriaux, ces institutions culturelles édifiées au croisement de la science et du politique qui ont pour objet le patrimoine, constituent d'excellents indicateurs (dans le présent) et des témoins (pour le passé) des représentations de "l'identité ", de ses propositions de définition théorique, de sa traduction muséographique et de ses usages politiques.

C'est ce que cet article se propose de montrer à travers le cas du passage des musées de la Nation aux musées de l'Europe que l'on observe dans plusieurs pays de l'Ouest de l'Europe depuis la fin des années 1980 et qui représente un phénomène remarquable dont il convient de saisir les enjeux et les implications, scientifiques et politiques. Il offre ainsi un angle d'approche privilégié pour saisir l'instrumentalisation du passé dans les constructions politiques et identitaires nationales et supranationales. Rappelons en effet le rôle assigné aux musées et notamment aux musées de culture et d'histoire dans les constructions nationales ${ }^{2}$. Assiste-t-on avec les musées de l'Europe à une reproduction de ce modèle à l'échelle européenne ?

1 À l'occasion du colloque " Musées et sociétés " qui se tint en France en 1991, la Direction des musées de France reconnaissait la valeur des musées autres que les musées d'art - justement appelés " musées de société » - dans leur fonction identitaire. Voir Éliane Barroso et Emilia Vaillant (éd.), Musées et sociétés, Actes du colloque de Mulhouse Ungersheim, juin 1991 - Répertoire analytique des musées, bilans et projets. Paris, ministère de l'Éducation et de la Culture, DMF, 1993, 446 p.

2 Voir notamment Anne-Marie Thiesse, La création des identités nationales, Europe XVIIIXX' siècles, Paris, Le Seuil, Points Histoire, 2001 [1999]. 
Pour le comprendre, j'ai réalisé une enquête de terrain sociohistorique et ethnographique auprès des différentes équipes de conception des projets de musées de l'Europe, dans plusieurs pays européens entre 2005 et 2010. Les résultats mis en évidence dans cet article sont principalement issus des observations et analyses réalisées à cette occasion sur les musées auto-désignés par leurs acteurs comme " musées de l'Europe ».

\section{Une nouvelle strate dans l'histoire des musées}

Si l'on en croit l'historien Krzysztof Pomian qui en annonçait la venue en $1991^{3}$, nous avons affaire avec l'avènement des " musées de l'Europe " à une cinquième strate dans l'histoire des musées de la Nation, correspondant à leur européanisation. Cette nouvelle phase, résultante des quatre précédentes, inaugure une tentative de redéfinition du musée d'identité, caractérisée par une volonté d'ouverture et d'hybridation. L'auteur montre en effet que dans l'histoire muséale - étroitement liée à l'histoire des sciences et à l'histoire politique -, la première strate correspond au moment où les collections particulières ou royales passent dans le domaine public pour former les premiers musées nationaux. Nous sommes alors au XVI siècle. La deuxième strate se situe quant à elle au XVIII siècle, autour de la Révolution française, qui généra des musées nationaux à visée universelle, illustrés par les musées d'antiquités et d'histoire nationale. La troisième strate lui succède, au XIX $\mathrm{X}^{\mathrm{e}}$ siècle, avec la création des États-nations, lorsque le musée alors investi par l'idéologie nationale devint une affaire d'État, en tant que lieu magistral d'institutionnalisation de la culture et de l'histoire nationales. Enfin, la quatrième strate serait apparue au $\mathrm{XX}^{\mathrm{e}}$ siècle, au lendemain de la Seconde Guerre mondiale, lorsque le musée influencé par les nouvelles manières de voir et d'écrire l'histoire, s'ouvrit aux sociétés contemporaines, industrielles et urbaines, en traitant de sujets du quotidien qui le détournent de la grande histoire. Aujourd'hui donc, surviendrait la cinquième strate : celle de l'ouverture à l'Europe des musées de la Nation.

À travers chacune de ces strates, c'est un rapport différencié à l'identité, à l'histoire et à la mémoire qui s'exprime, sans cesse renégocié au fil de l'histoire des sciences et de l'histoire politique des pays auxquels appartiennent les musées. De telle sorte qu'ils peuvent être considérés comme des traces historiques de ces rapports et érigés en objets d'étude contemporains, pour qui s'intéressent à cette question.

En atteste le cas des musées nationaux de culture et d'histoire, tous deux liés à la construction des identités nationales en Europe et aujourd'hui pris dans de profondes transformations. Appartenant au groupe des musées de société, considérés comme caractérisés par leur lien « ontologique avec l'iden-

3 Voir Krzysztof Pomian, "Musée, nation, musée national ", Le débat, 65, mai-août, 1991, p. 166-175. 
tité " ${ }^{4}$, les musées historiques et ethnographiques, au-delà de leurs fonctions scientifiques et muséographiques primordiales (d'inventaire et de collecte, de conservation et de recherche, de présentation et aujourd'hui de médiation), ont eu, jusqu'à présent, la vocation à la fois sociale et politique, de représenter

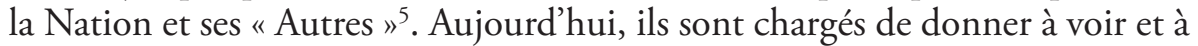
penser une représentation plus complexe de l'identité, en échos à la mondialisation et au paradigme devenu dominant de la diversité culturelle.

C'est dans cette perspective que depuis une trentaine d'années à peu près partout en Europe, d'importants bouleversements touchent le paysage des musées nationaux. De manière tout à fait conjoncturelle, cette grande transformation est liée au contexte socio-politique de la fin des années 1980 et aux débats scientifiques et intellectuels qui surviennent autour de «l'identité » avec la fin de la Guerre-froide, le post-colonialisme, les résurgences nationalistes, les conflits ethniques, les difficultés du processus de construction européenne et les inquiétudes à l'égard de la globalisation. En effet, à un moment où "l'identité » sent le soufre, où « l'identité nationale » est remise en question ou survalorisée, où "l'identité européenne » en lien avec la notion de " citoyenneté européenne " devient une nouvelle catégorie d'intervention publique qui ne parvient pas à faire consensus ${ }^{6}$ et enfin, où " la diversité culturelle » est devenue un paradigme banalisé des politiques publiques, que faire des musées nationaux de culture et d'histoire en prise avec un sujet aussi brûlant que celui des "identités culturelles " ? Comment parler désormais des histoires et des cultures, quels récits des origines fournir à la Nation, comment classer, catégoriser, représenter les cultures ? Quel rôle politique assigner au musée, jusqu'alors outil privilégié de représentation et de légitimation de la Nation?

Pour apporter des réponses à ces questions épineuses, face à des institutions nationales " en crise $»^{7}$, jugées dépassées (en regard des avancées de la muséologie, obsolètes sur le plan scientifique et résolument inadaptées du

4 Voir à ce sujet Serge Chaumier, Des musées en quête d'identité, Écomusée versus Technomusée, Paris, L'Harmattan, 2003 et Serge Chaumier, «L'identité, un concept embarrassant, constitutif de l'idée de musée ", Culture \& Musées, n 6, 2005, p. 21-42.

5 Sur les musées de la Nation, voir Dominique Poulot, Patrimoine et musées : l'institution de la culture, Paris, Hachette, 2001, 224 p. Sur les musées des " autres ", voir Sally Price, Paris Primitive: Jacques Chirac's Museum on the Quai Branly, Chicago, University of Chicago Press et Benoît de L'Estoile, Le goût des autres. De l'Exposition coloniale aux arts premiers, Paris, Flammarion, 2007.

6 Voir notamment Yves Déloye, "De la citoyenneté stato-nationale à la citoyenneté européenne : quelques éléments de conceptualisation ", Swiss Political Science Review, 4(4), été 1998, p. 169-194 ; Jean-Marc Ferry, "L'État européen ", in Kastoryano Riva (éd.), Quelle identité pour l'Europe ? Le multiculturalisme à l'épreuve, Paris, Presses de la FNSP, 2005 (1998); Paul Magnette, La citoyenneté européenne, Bruxelles, Éditions de l'ULB, 1999, p. 119.

7 Sur cette question de la " crise », voir Camille Mazé, Frédéric Poulard, Christelle Ventura (éd.), Musées d'ethnologie. Culture, politique, changement institutionnel, Éditions du CTHS, Paris, 2013, 149 p. 
point de vue de la pensée politique), si de rares établissements se maintiennent en l'état, en parallèle de cette survie improbable a lieu une prolifération de projets muséographiques - qui resteront pour certains sans lendemain - sous l'impulsion d'acteurs très divers (professionnels de musées, hommes politiques, intellectuels, scientifiques, acteurs de la "société civile »). L’on ne compte plus les musées qui ferment, sont transformés, déplacés, restructurés, revisités de fond en comble ou crées de toutes pièces. De nouveaux nés tentent de sortir de terre à partir de rien, tandis que d'autres, édifiés sur les ruines de leurs ancêtres déchus, préfèrent se nourrir de leurs poussières. Tous veulent revisiter les cultures, raconter autrement les origines, fixer de nouvelles histoires, forger des mémoires ${ }^{8}$ plus consensuelles, donner à voir des identités plus complexes et plus justes.

C'est dans cette conjoncture précisément que les projets de " musées de l'Europe " voient le jour ${ }^{9}$; et avec eux le projet d'européaniser ${ }^{10}$ le modèle polymorphe et solidement institué du musée de la Nation. Ils expriment l'enjeu aujourd'hui devenu crucial pour certains (professionnels des musées, décideurs politiques, intellectuels, entrepreneurs culturels ou économiques) de parvenir à dépasser les visions nationalo-centrées des musées historiques et ethnographiques, d'inventer une nouvelle génération de musées capable de montrer la culture et de raconter l'histoire au-delà du national, dans une dimension " européenne ». Dans ces musées postnationaux, les visiteurs européens trouveraient de quoi se forger une image commune de leur culture, de quoi se nourrir d'une histoire sur lequel asseoir le projet européen difficile (impossible ?) à bâtir en regard du passé douloureux et divisé de l'Europe.

8 Marie-Claire Lavabre, "Usages et mésusages de la notion de mémoire ", Critique internationale, $\mathrm{n}^{\circ} 7$, avril 2000, p. 48. La "mémoire » est un concept des sciences sociales ou plus précisément une notion - largement polysémique et, en tant que telle, objet de controverses - mobilisée par des observateurs et analystes. Elle constitue également un phénomène social, nommé comme tel par des acteurs sociaux et/ou politiques. Là réside une première difficulté. ", in MarieClaire Lavabre, "Paradigmes de la mémoire ", Conférence inaugurale au musée du Quai Branly, Transcontinentales, $\mathrm{n}^{\circ}$ 5, $2^{\mathrm{e}}$ semestre, 2007, p. 139-147.

9 L'application de la notion d'européanisation aux musées de l'Europe a été proposée par Camille Mazé, La fabrique de l'identité européenne. Dans les coulisses des musées de l'Europe, Paris, Belin, Socio-histoires, 2014, 320 p. Voir également Camille Mazé, "Von Nationalmuseen zu Museen der Europäischen Kulturen. Eine sozio-historische und ethnographische Annäherung an den Prozess eine ,Europäisierung" der ethnologischen und historischen Nationalmuseen ", Museumskunde. Provenienzforschung und Restitution, G + H, vol. 73, n 1/08, Berlin, 2008, p. 110-126. Cette notion a ensuite été reprise par Wolfram Kaiser, Stefan Krankenhagen, Kerstin Poehls, Exhibiting Europe in museums: transnational networks, collections, narratives, and representations, Berghahn Books, Museums and collections, Oxford, 2014 et Europa ausstellen. Das Museum als Praxisfeld Europäisierung, Köln, Böhlau Verlag, 2012, 278 p.

10 Pour une synthèse sur la notion d'européanisation telle qu'elle est abordée en science politique, voir Sabine Saurugger, Théories et concepts de l'intégration européenne, Paris, Presses de la FNSP, 2009. 
Guidés par cette ambition, plusieurs projets de "musées de l'Europe " ${ }^{11}$ ont été élaborés en moins de trente ans. En Allemagne, à Berlin d'abord, c'est le Deutsches Historisches Museum (Musée historique allemand) qui a été créé au début des années 1990, sous l'impulsion du chancelier Helmut Kohl, avec la mission de présenter l'histoire de l'Allemagne dans une perspective européenne. En ce sens, il peut être considéré comme un pionnier des "musées de l'Europe ». Au même moment, le musée d'ethnologie nationale (Museum für Volkskunde) se voyait réorienté en un " musée des cultures européennes " (Museum Europäischer Kulturen). En France, l'Historial de la Grande Guerre de Péronne ouvert en 1992 dans la Somme, en donnant la parole sur le même plan aux trois nations belligérantes (la France, l'Allemagne et l'Angleterre) apparaît également comme un précurseur en matière d'européanisation des musées d'histoire et de dénationalisation du regard ${ }^{12}$. À Strasbourg, l'idée de dédier à l'Europe un lieu muséal et culturel existe également depuis longtemps; après des années de recherche de soutiens politiques et financiers, la première pierre du Lieu d'Europe a enfin été posée récemment (en juin 2013). Autre projet initialement programmé en France, censé mettre l'Europe à l'honneur dans un grand musée de société : le musée des civilisations de l'Europe et de la Méditerranée. Ex-musée national des Arts et Traditions populaires de Paris (MNATP) délocalisé en région, le MuCEM a finalement ouvert ses portes au public en mai 2013 à Marseille (alors Capitale européenne de la culture), mais sous la bannière de "grand musée des cultures de la Méditerranée ". En Belgique aussi, deux projets de musées de l'Europe ont vu le jour. En 1997 tout d'abord, le Musée de l'Europe a été fondé à Bruxelles sous la forme d'une association (ASBL) placée sous le haut patronage de deux personnalités de la vie belge et européenne, Antoinette Spaak et de Karel van Miert. Dénué de collections et de lieu fixe, il opère sur le mode de l'itinérance en diffusant ses expositions à travers l'Europe. À sa suite, le projet de Maison de l'histoire européenne est né, porté par le Parlement européen ; elle semble aujourd'hui en bonne voie et devrait ouvrir ses portes à Bruxelles à l'automne 2015 dans le quartier des institutions communautaires. Enfin au Luxembourg, le Musée européen Schengen, une initiative conjointe de l'État luxembourgeois et de la ville de Schengen, a été inauguré en juin 2010 à l'occasion de l'anniversaire des accords éponymes.

11 L'expression indigène " musées de l'Europe ", que je reprends à mon compte pour mieux l'interroger, a été formalisée lors d'un colloque organisé en 2000 à Turin sur le thème du musée, de l'identité et de l'Europe : Europa e Musei, Identità e rappresentazioni. Europe and museums, Identities and representations, Europe et musées, Identités et représentations, Actes du colloque de Turin, 5-6 avril 2001, Turin, Celid, 2001.

12 Sur l'Historial de Péronne et plus largement sur les musées d'histoire et les musées des guerres du XX $X^{\mathrm{e}}$ siècle, voir Sophie Wahnich (éd.), Fictions d'Europe, la guerre au musée, Allemagne, France, Grande-Bretagne, Paris, Éd. des Archives contemporaines, 2002. 
Conjointement à ces projets aboutis ou en cours de réalisation, certains desseins sont restés sans lendemain. En 1996, des membres de la Commission européenne pour la Démocratie par le Droit (la Commission de Venise) appelaient de leurs vœux la création d'un Musée de l'Union au sein d'un district européen à Luxembourg. Projet resté sans suite. La même année en Italie, la ville et la Province de Turin, préparant leur candidature au titre de Capitale européenne de la culture, proposèrent la création d'un musée de l'Europe, dénommé Museion per l'Europa. Projet avorté. Quelques années plus tard, l'idée de créer un centre muséal et culturel dédié à l'Europe surgit à Aix-la-Chapelle sous l'appellation de Bauhaus Europa. La population aixoise fut invitée à se prononcer par référendum le 10 décembre 2006. Projet rejeté. Finalement donc, ce ne sont pas moins de dix projets de " musées de l'Europe » qui ont été imaginés.

\section{Le musée : un indicateur du rapport de la science et du politique à «l'identité »}

Force est de constater que les projets afin de créer des musées de l'Europe sont géographiquement concentrés dans quelques pays de l'Ouest de l'Europe. Et plus précisément, cinq des six pays de "la vieille Europe ", fondateurs de la Communauté européenne du Charbon et de l'Acier (CECA) $)^{13}$ et signataires du Traité de Rome instaurant la communauté européenne ${ }^{14}$ : l'Allemagne, la Belgique, la France, l'Italie et le Luxembourg. Aucun projet de musée de l'Europe donc, ni dans le Nord, ni dans le Centre, ni dans l'Est de l'Europe. Cette localisation reflète les trois grandes orientations que l'on peut schématiquement distinguer dans les musées nationaux d'ethnologie et d'histoire européens à partir du tournant de 1989 (die Wende) et jusqu'au début des années 2000 : la stabilité (dans le Nord) ; l'ouverture (à l'Ouest, qui prend la voie d'une européanisation ou d'une internationalisation); et le retour au national (au Centre et à l'Est). De plus, chacune de ces tendances ${ }^{15}$ résulte d'un investissement politique différencié dont les musées d'ethnologie et les musées d'histoire ${ }^{16}$ ont pu faire l'objet par le passé et dont ils font aujourd'hui

13 La République fédérale d'Allemagne, la France, l'Italie, la Belgique, les Pays-Bas et le Luxembourg fondèrent la CECA sous le traité signé à Paris le 18 avril 1951.

14 Le traité constituant l'acte fondateur de la Communauté économique européenne (CEE), signé le 25 mars 1957 par l'Allemagne, la France, l'Italie et les trois pays du Benelux (Belgique, Luxembourg, Pays-Bas), dénommé TCE, Traité de Rome ou Traité CE.

15 Nadia Guzin Lukic, «Identité, diversité et nation dans les Musées d'ethnographie en Croatie », Ethnologies, Annual, 2002. Voir aussi Krzysztof Pomian, "Les musées d'ethnographie dans l'Europe d'aujourd'hui ", in Rencontres européennes des musées d'ethnographie. Actes des premières rencontres des musées d'ethnographie, 1993, Paris, Musée national des Arts et Traditions populaires/École du Louvre, 1996, p. 37-48.

16 Pour le cas allemand par exemple, voir Isabelle Benoit, Politique de mémoire: les musées d'histoire français et allemands 1945-1995, Thèse de doctorat, Institut Universitaire euro- 
encore l'objet selon qu'ils sont situés dans des États-nations déjà constitués, dans des ensembles où l'État national reste à construire, dans des États pris dans la dynamique postnationale ou dans celle du retour au national.

Ainsi, jouant un rôle différencié dans la construction des identités (le musée d'ethnographie a souvent précédé l'État-nation tandis que le musée historique rend compte de sa création), ces deux types de musées méritent d'être traités sur le même plan, en tant qu'instrument possible de l'action publique historique et mémorielle ${ }^{17}$, capables de fixer les cadres d'une " mémoire collective nationale ${ }^{18}$, en tant qu'élément parmi d'autres du mécanisme de construction et d'institutionnalisation de l'État-nation et qu'outil de représentation ou de création des identités nationales ${ }^{19}$ capable de contribuer à forger le sentiment d'appartenance à la " communauté imaginée ${ }^{20}$ dans un but patriotique. Ils ont en effet toujours fonctionné en miroir et il est aujourd'hui significatif qu'ils constituent les deux types de musées en prise avec la question de l'européanisation, là où "l'identité nationale " semble à tout prix devoir faire l'objet à la fois d'une déconstruction et d'une ouverture. Ces musées sont particulièrement présents dans les pays de l'Ouest de l'Europe, là où la culture légitime et l'image de la Nation ont été érigées sur la base de " la haute culture ${ }^{21}$ et où les musées des Beaux-arts et les monuments historiques recouvrent une légitimité culturelle et politique plus grande que les musées nationaux d'ethnologie et d'histoire. La France en constitue un exemple emblématique avec le Louvre qui incarne le musée national patriotique par excellence, tandis qu’à ses côtés

péenne de Florence et Institut d'Études Politiques de Grenoble, 1021 p. + annexes, 2001 ; Michael Werner, "Deux nouvelles mises en scène de la nation allemande. Les expériences du Deutsches Historisches Museum (Berlin) et du Haus der Geschichte der Bundesrepublik Deutschland (Bonn)", in François Hartog, Jacques Revel, Les usages politiques du passé, Paris, Éd. de l'EHESS, 2001, p. 77-97.

17 Sur les politiques du passé, voir Claire Andrieu, Marie-Claire Lavabre, Danielle Tartakowsky (éd.), Politiques du passé, Aix-en-Provence, Presses Universitaires de Provence, 2006 ; Aleida Assmann, Der lange Schatten der Vergangenheit. Erinnerungskultur und Geschichtspolitik, München, Beck, 2006 ; Astrid Erll (éd.), Cultural Memory studies. An international and interdisciplinary handbook. Berlin, De Gruyter, 2008 ; Camille Mazé, "Zwischen Geschichts- und Gedächtnispolitik: Europäisierung nationaler Museen », in Étienne François, Kornelia Konczal, Robert Traba, Stefan Troebst, (Hg.), Strategien der Geschichtspolitik in Europa nach 1989. Deutschland, Frankreich und Polen im Vergleich, Göttingen, Wallstein, 2013.

18 Sur la notion de mémoire collective, voir Maurice Halbwachs, La mémoire collective, Paris, PUF, 1950 et Les cadres sociaux de la mémoire, Paris, Albin Michel, 1952, p. 79.

19 Anne-Marie Thiesse, La création des identités nationales, Europe XVIII'-XXe siècles, Paris, Le Seuil, Points Histoire, 2001 [1999].

20 Pour une définition de la notion de "communauté imaginée ", voir Benedict Anderson, L'imaginaire national, réflexions sur l'origine et l'essor du nationalisme, Paris, La Découverte, 2002 [Imagined Communities: Reflections on the Origins and Spread of Nationalism, Londres, Verso, 1983].

21 Ernest Gellner, Nations et nationalisme. Paris, Payot \& Rivages, 1999 [Nations and Nationalism. Oxford, Basil Blackwell, 1983]. 
le musée national des Arts et Traditions populaires fait pâle figure ${ }^{22}$. À l'inverse, là où "l'art national " a été construit sur la base de la " culture populaire ${ }^{23}$ comme dans les pays du Nord, du Centre et de l'Est de l'Europe, les musées d'arts et traditions populaires recouvrent une plus grande notoriété. En la matière, le rôle précurseur du musée ethnographique de Stockholm (Musée Nordique et Musée de plein-air Skansen, 1872) ${ }^{24}$ dont le fondateur affichait clairement le but patriotique du musée, n'est plus à prouver :

Chaque peuple doit posséder un jour son musée d'ethnographie nationale, où il viendra tremper sans cesse sa culture indigène et chercher dans les souvenirs des générations passées des exemples de patriotisme, des modèles et des motifs propres à conserver à ses travaux et à son activité une large et puissante empreinte nationale. ${ }^{25}$

Comme en écho à ces différences de répartition et de valeur assignée à tel ou tel type de musée en fonction des régions d'Europe lors de la première phase de nationalisme (création des États-nations au XIX siècle et au début $\mathrm{du} \mathrm{XX}^{\mathrm{e}}$ siècle $)^{26}$, l'histoire semble aujourd'hui se répéter à travers les orientations différenciées que les musées de société nationaux prennent selon les zones. Pourtant, le contexte n'est pas le même (européanisation, second nationalisme ${ }^{27}$ ). Dans le Nord de l'Europe, dans les pays peu secoués par les boulever-

22 Le MNATP a été créé en 1937. Jusqu'alors, la présentation du folklore national était restreinte à une petite pièce du musée d'Ethnographie du Trocadéro (Paris, 1884), la «Salle de France ». Voir Nélia Dias, Le musée d'ethnographie du Trocadéro, 1879-1908 : anthropologie et muséologie en France, Presses du CNRS, 1991.

23 Ioana Popescu, «L'art national chez les Roumains », Terrain, 17, 1991.

24 De là partit un vaste mouvement de création de "musées du peuple " à travers toute l'Europe, censés participer à l'élaboration des symboles nationaux et à la politique d'image de la Nation en tant que lieu à laquelle il fallait adhérer. À partir de 1878, les inaugurations de musées d'ethnologie nationale s'enchaînèrent : Dansk Folkemuseum (Musée danois de folklore, Copenhague , 1885) ; Museum für deutsche Volkstrachten und Erzeugnisse des Hausgewerbes (Musée des costumes et ustensiles domestiques populaires allemands, Berlin, 1889 ; Etnografisk Museum (Musée d'ethnographie générale de l'université d'Oslo, 1894), annexé par la création du Norsk folkemuseum (Musée national de folklore) ; Österreichisches Museum für Volkskunde (Musée autrichien de folklore, Vienne, 1895) ; puis Prague ; Sofia ; Bucarest... Tous ces musées semblent faire écho à l'appel de Skansen. Cf. Nils-Arvid Bringeus, "Artur Hazelius and the Nordic Museum », Ethnologia Scandinvica, vol. P., 1974, p. 5-16; Marc Maure, "Nation, paysan et musée. La naissance des musées d'ethnographie dans les pays scandinaves (1870-1904) », Terrain, «La mort », 20, mars 1993, p. 147-157.

25 Jules Henri Kramer à propos d'Arthur Hazelius, cité dans Anne-Marie Thiesse, op. cit., p. 159.

26 Éric J. Hobsbawm, Nations et nationalismes, depuis 1780 : programme, mythe, réalité. Paris, Gallimard, 1997 [Nations and Nationalism since 1780. Cambridge, Cambridge University Press, 1990] ; Éric J. Hobsbawm et O. Terence Ranger (éd.), L’Invention de la tradition. Paris, Éditions Amsterdam, 2006 [The Invention of Tradition. Cambridge, Cambridge University Press, 1983].

27 Pour la distinction entre premier et second nationalisme, voir Jean-François Gossiaux, Pouvoirs ethniques dans les Balkans, Paris, PUF, 2002. Sur les conflits et les résurgences nationalistes, voir aussi Alain Dieckhoff, La nation dans tous ses états. Les identités nationales en mouvement, Paris, Champs Flammarion, 2000. 
sements géopolitiques contemporains, là où la notion d'identité nationale et ses outils de représentation symbolique restent légitimes, la tendance est à la stabilité du modèle du musée de la Nation. L'emblème de cette stabilité : la notoriété de Skansen et autres musées d'ethnographie et de plein-air en Suède, Norvège, Finlande et Danemark. Au Centre et à l'Est en revanche, dans les ex-Républiques soviétiques d'Europe en pleine résurgence nationaliste suite à l'effondrement de l'URSS, où " la culture nationale " a été édifiée en grande partie sur la reconnaissance du populaire au moment de la création des États-nations, l'heure est à la déconstruction du patrimoine communiste et à la réhabilitation de l'ancien modèle. Dès le début des années 1990, des élites soucieuses de se défaire du carcan du musée soviétique élaboré dans les années 1920 en Russie et diffusé dans toutes les nations sous domination soviétique après 1945 avec pour mission de mettre en scène la vision marxiste-léniniste du monde ${ }^{28}$, entreprennent son démantèlement. Deux orientations se dessinent alors : conserver et exposer afin d'entretenir la mémoire du totalitarisme ou détruire et réhabiliter les musées de la Nation originels. Dans cette veine, à Budapest par exemple, aux côtés du Musée national hongrois qui retrace l'histoire de la Hongrie depuis l'Antiquité jusqu'à la chute du communisme, le Parc des Statues (Szoborpark) donne à voir depuis 1993 les statues monumentales édifiées dans la période communiste (1949-1989) à l'effigie de Lénine, Marx, Engels et autres leaders du communisme hongrois. Ici, le musée-mémorial opère un travail de dénonciation que l'on retrouve sous une autre forme à la Maison de la terreur (2002) qui retrace l'histoire du nazisme et du communisme en Hongrie afin d'honorer le " devoir de mémoire " du totalitarisme. Plutôt que détruire les traces de ce passé douloureux ${ }^{29}$, on choisit de les exposer pour en entretenir la mémoire ; dans le même temps, les faire entrer au musée et les patrimonialiser permet de les inscrire dans un passé révolu ${ }^{30}$. Autre exemple à Bucarest où le musée du Paysan roumain, particulièrement emblématique de ce renouveau, opère sous une forme différente de la Hongrie mais dans le même dessein. Issu de la reconversion du Musée d'ethnographie et d'art national créé en 1901, ce musée fut rebaptisé Musée national d'Art populaire en 1951 après l'instauration du régime communiste, puis Musée Lénine-Staline en 1955 avant d'être appelé Musée Marx-Engels-Lénine après la déstalinisation et, enfin, Musée du Parti communiste roumain avant la chute du régime. Après 1989, le ministère de la culture roumain décida de refonder le musée national dans son esprit d'origine,

28 À ce sujet, voir Aurélie Gosselin, La politique des musées russes : 1917-1991, Paris, Larousse, $1993,283 \mathrm{p}$.

29 Georges Mink, Laure Neumayer (éd.), L’Europe et ses passés douloureux, Paris, La Découverte, 2007, p. 222-232.

30 Voir Anne-Marie Losonczy, "La muséification du passé récent en Hongrie post-communiste : deux mises en spectacle de la mémoire ", Revue d'études comparatives Est-Ouest, vol. 37, n 3, 2006, p. 97-112. 
marqué par le regard ethnographique et l'intérêt pour le populaire et la nation roumaine : ce sera le Musée du paysan roumain consacré au paysan comme figure de "l'homme traditionnel " européen ${ }^{31}$. Aujourd'hui, lorsque l'on visite ce musée, on est frappé par la présence de la religion orthodoxe qui y a retrouvé ses quartiers et on se laisse surprendre par la « salle communiste » au sous-sol où des objets à l'effigie du communisme, auparavant solennellement exposés dans ce même musée, sont présentés dans une ambiance kitch destinée à les tourner en dérision. On pourrait poursuivre la liste à travers le cas croate ou polonais avec le futur musée national de l'Histoire de la Pologne et l'ouverture, en avril 2013, du Musée d'histoire des juifs polonais. Mais plutôt que de multiplier les exemples, ce qu'il faut retenir ici, c'est la tendance dans les pays postsoviétiques au recentrage sur le national et l'absence concomitante de projets de musées de l'Europe en tant que tels.

À l'inverse, à l'Ouest, en particulier dans les pays historiquement moteurs dans le processus de construction européenne, engagés dans la critique de l'identité nationale et dans la dynamique postcoloniale, le modèle du musée de la Nation connaît un ébranlement ${ }^{32}$. Ici, en résonance avec l'idéologie universaliste, la rhétorique du relativisme, les rêves de cosmopolitisme et la nouvelle norme du "dialogue entre les cultures $»^{33}$, nombreux sont les musées à être remis en question et à entamer leur reconversion au profit d'une ouverture à l'Europe ou à l'international. Certains auteurs parlent de crise, d'autres préferent parler de bouleversement du paysage muséal ou de changement institutionnel. Mais partout, le constat est le même : en pleine effervescence patrimoniale, tandis que les "petits musées " se développent partout sur "le territoire ", les grands musées de société rencontrent des difficultés ${ }^{34}$. Pour eux, le changement semble s'imposer.

31 Pour l'histoire de ce musée, voir Irina Nicolau, "Le Musée du Paysan roumain. Histoire et histoires ", Ethnologie française, 1995, vol. 25, n 3.

32 Camille Mazé, «Les musées de l'Europe. Vacillement ou renforcement du modèle du musée national ? ", in Hanna Murauskaya, Anne-Solène Rolland (éd.), Les musées de la nation : créations, transpositions, renouveaux. Europe, XIXe-XXIe siècles, Paris, L'Harmattan, 2008, p. 123-142.

33 Dès l'après-guerre, la diversité culturelle est présentée comme le gage de la paix et de la sécurité internationale et comme le garant de la survie des cultures face au risque de l'homogénéisation encouru à cause de la mondialisation et notamment de l'hégémonie américaine. D'abord appelée exception culturelle, puis diversité culturelle et aujourd'hui dialogue entre les cultures ou les civilisations, cette notion est devenue, entre les années 1990 et 2000, un nouveau paradigme des politiques publiques en matière culturelle. Voir Lluis Bonnet, Emmanuel Négrier (éd.), La fin des cultures nationales? Les politiques culturelles à l'épreuve de la diversité, La Découverte, Recherches, Mercuès, 2008, 230 p. et Emmanuel Négrier, "La diversité, nouveau paradigme des politiques culturelles ? Une comparaison européenne ", RIPS, Université de Saint-Jacques-de-Compostelle/ESP, 7(1), 2008, p. 95-110. Voir également Philippe Poirrier, L'État et la culture en France au XX' siècle, Paris, Le Livre de Poche, 2006 [2000], 250 p.

34 Voir Camille Mazé, Frédéric Poulard, Christelle Ventura (éd.), Musées d'ethnologie, op. cit. 
Pour cela, du côté des musées d'ethnologie exotique, les " musées des autres $\|^{35}$ tentent de se défaire de leur ethnocentrisme pour s'ouvrir aux " cultures du monde ". Le Musée d'ethnographie de Neuchâtel rénové à partir de 1980 constitue un peu l'emblème de ce renouveau, également incarné par le musée de la Civilisation de Québec (1988). Après eux, d'autres projets dédiés à une vision postnationale ou postcoloniale des "cultures du monde " voient le jour : l'Esplanade des mondes à Genève (abandonné en 2001), le Musée national des cultures du monde à Göteborg (ouvert en 2004), le musée du Quai Branly à Paris (ouvert en 2006). Du côté des musées d'histoire, on hésite encore entre la Nation, l'Autre, l'Europe et le monde. Si ces dernières années, on assiste à un regain de projets de musées d'histoire nationale (Maison de l'histoire de l'Autriche, Maison de l'histoire de France sous le quinquennat du président Sarkozy, Maison de l'histoire de la Hollande), les efforts vont plutôt vers la création de musées d'histoire comparatistes, comme à Péronne par exemple avec l'Historial de la Grande-guerre depuis 1992, ${ }^{36}$ ou de musées redonnant leur place à des acteurs oubliés de l'histoire nationale, comme la Cité nationale de l'histoire de l'immigration, inaugurée en 2007 à Paris $^{37}$. C'est dans ce paysage muséal en cours de redéfinition que les différents musées de l'Europe émergents tentent de se faire une place, non sans concurrence les uns avec les autres. Ils sont pensés comme les "lieux de mémoire " qui manquent à l'Europe.

\section{Les « lieux de mémoire » qui manquent à l'Europe...}

En résonance avec l'action publique européenne et communautaire dans le domaine culturel, mais surtout en héritage des modalités de constructions identitaires mises en œuvre à l'échelon national et dans les musées de la Nation, les entrepreneurs des musées de l'Europe accordent en effet une attention privilégiée à la culture et au passé. Ce sont deux registres traditionnellement mobilisés dans les opérations de construction identitaire à l'échelon national ${ }^{38}$. Ils déclarent explicitement vouloir contribuer à l'émergence et à la formalisation de "l'introuvable mémoire européenne " " croire dans

35 Sur l'ethnologie exotique, voir Alban Bensa, La fin de l'exotisme, Toulouse, Anacharsis, 2006, 368 p. Sur l'exotisme en lien avec le musée, voir Marc-Olivier Gonseth (et al.), Le musée cannibale, Neuchâtel, Musée d'ethnographie, 2002.

36 Voir Sophie Wahnich (éd.), Fictions d'Europe, op. cit.

37 Une partie des historiens engagés dans ce projet s'en retirèrent en 2007, à l'annonce de la décision du Président Sarkozy de créer un ministère de l'immigration et de l'identité nationale.

38 Yves Déloye (éd.), « La socio-histoire et l'intégration européenne », Politique européenne, $\mathrm{n}^{\circ} 18$, hiver 2006, p. 5-154.

39 Marie-Claire Lavabre, "Actualité de la mémoire à l'Ouest ", in Marie-Christine Maurel et Françoise Mayer (éd.) (2008), L’Europe et ses représentations du passé, les tourments de la mémoire, Paris, L'Harmattan, Logiques sociales, 224 p., p. 51-55, 2008. 
la nécessité d'un "passé partagé pour un avenir commun ${ }^{40}$ et déplorer "le décrochage de l'histoire dans les générations actuelles ", le " désintérêt pour le passé qui semble ne plus les concerner vraiment ", la " méconnaissance de l'histoire de l'unification européenne " qui semble trop facilement acquise ${ }^{41}$. C'est pour remédier à ces lacunes qu'ils entreprennent de doter l'Europe des "lieux de mémoire » qui lui font défaut ${ }^{42}$.

Bien qu'il ne soit pas reconnu que la notion de "lieu de mémoire ", mise en évidence pour le cas français par l'historien Pierre Nora, soit exportable aux autres pays européens et applicable à "l'Europe » elle-même ${ }^{43}$, les musées de l'Europe sont bel et bien conçus comme les "lieux de mémoire " qui lui manquent. L'Historial de la Grande-guerre de Péronne, décrit comme «le lieu de l'invention d'une mémoire européenne pour le présent $~_{44}$, est fréquemment cité en exemple par les entrepreneurs des musées de l'Europe. Et, de manière significative, c'est l'historien Jacques Le Goff, qui appelait déjà de ses vœux en 1990 l'émergence de lieux de mémoire européens ${ }^{45}$, qui fut choisi pour ouvrir le colloque "Europa e musei " ${ }^{46}$, fondateur dans la genèse des "musées de l'Europe".

Les premiers porteurs du MuCEM déclaraient par exemple en 1999 que le musée est censé « constituer l'un des lieux où l'Europe se construit en construisant sa mémoire et en fondant son identité, en intégrant son histoire passée à ce qu'il y a de plus actuel dans son évolution $»^{47}$. Un peu plus tard, lors du colloque "Europa e musei ", les porteurs du projet turinois évoquaient à leur tour cette temporalité enchevêtrée dans leurs contributions significativement intitulées "Un musée pour comprendre l'Europe et construire le futur ${ }^{48}$ et " Donner

40 "Musée de l'Europe. Un passé partagé pour un avenir commun », Documents préparatoires. Comité international des directeurs de musées, 24 janvier 2004, p. 38.

41 Musée de l'Europe, "Le projet culturel ", Cahier 4, Tempora, 2004, p. 5.

42 Voir Sonja Kmec, Benoît Majerus, Michel Margue, Pit Péporté, Dépasser le cadre national des "Lieux de mémoire ". Innovations méthodologiques, approches comparatives, lectures transnationales, Peter Lang, Berne, 2009.

43 Voir Étienne François, Hagen Schulz, Mémoires allemandes, Paris, Gallimard, 2007, 800 p. et Étienne François, Kornelia Konczal, Robert Traba, Stefan Troebst (Hg.), Geschichtspolitik..., op. cit., p. 491-513.

44 Voir Jean-Yves Boursier (éd.), Musées de guerre et mémoriaux, Paris, Éd. MSH, 2005, p. 80-81.

45 Voir à ce sujet Gérard Bossuat, «Des lieux de mémoire pour l'Europe unie ", Vingtième Siècle. Revue d'histoire, $\mathrm{n}^{\circ}$ 61, janvier-mars 1999, p. 56-69.

46 Europa e Musei, Identita e rappresentazioni. Europe and museums, Identities and representations, Europe et musées, Identités et représentations, Actes du colloque de Turin, 5-6 avril 2001, Celid, Turin, 2001.

47 Michel Colardelle, "Le Musée et le centre interdisciplinaire d'étude des civilisations de l'Europe et de la Méditerranée. Étude préalable pour un projet de délocalisation du MNATPCEF de Paris à Marseille », 1999 (Rapport consultable sur le site Internet du ministère de la Culture et de la Communication).

48 Valter Giuliano, "A museum for understanding Europe and build the future », Europa e Musei, op. cit., p. 15-20. 
un présent au futur : un musée pour l'Europe ${ }^{49}$. Les entrepreneurs du Lieu d'Europe (Strasbourg) parlent quant à eux d'un " Haut lieu de mémoire, d'histoire, de connaissance ». Et à son tour, le président du Parlement européen appelle de ses vœux la création d'un " lieu de mémoire et d'avenir » :

Je souhaite que l'on crée un lieu de mémoire et d'avenir où l'idée européenne puisse prospérer. Je propose la création d'une " Maison de l'histoire européenne ». (...) Il devrait s'agir [...] d'un lieu entretenant la mémoire de l'histoire européenne et de l'unification européenne. ${ }^{50}$

Autrement dit, les musées de l'Europe sont explicitement pensés comme un acteur social de "la mémoire ", elle-même conçue comme la présence du passé dans le présent ${ }^{51}$ et considérée comme constitutive de "l'identité ». Les entrepreneurs, aspirant à se substituer à l'inexistante politique européenne d'histoire et de mémoire, ambitionnent de se faire entrepreneurs de mémoire européenne $^{52}$. Cette volonté s'inscrit dans la continuité des débats scientifiques, intellectuels et politiques sur l'historiographie nationale, européenne et internationale (retour du refoulé dans les années 1960 en Allemagne, grande histoire et micro-histoire, doute épistémologique à partir des années 1980, problèmes liés aux histoires nationales et à l'écriture d'une histoire européenne, responsabilité de l'historien, travail mémoriel et usages politiques du passé). De là, naissent les propositions de réorientation des musées d'histoire nationale et de créations des musées de l'Europe qui ont vocation à aider à créer "l'identité européenne ». Ainsi, de manière générale et quasi unanime, les notions de "citoyenneté européenne ", "d'identité européenne ", de " conscience européenne " ou "d'esprit européen " sont placées à l'horizon des différents projets. En faisant de ces notions leurs principaux registres d'action et en s'auto-désignant entrepreneurs d'Europe ${ }^{53}$ en faveur de la " cause européenne " au service de laquelle ils mettent le musée, les entrepreneurs livrent leurs raisons d'agir les plus nobles - et les plus avouables. Le caractère interventionniste est particulièrement assumé par les porteurs du projet de Musée de l'Europe (Bruxelles). Ce sont ceux qui vont le plus loin dans l'affirmation et la revendication du caractère identitaire de leur entreprise :

49 Ugo Perone, "Giving a Present to the Future: a museum for Europe ", Europa e Musei, ibid., p. $21-28$ (p. 27).

50 Communiqué de presse "Le Bureau du PE décide de créer une "Maison de l'Histoire de l'Europe" ", 16/12/2008.

51 Marie-Claire Lavabre, "Paradigmes de la mémoire... ", art. cit.

52 Voir Michaël Pollak, Une identité blessée, Paris, Métailié, 1993 et notamment " Mémoire, oubli, silence ", p. 30 et s. Voir aussi Sarah Gensburger, Les Justes de France. Politiques publiques de la mémoire, Paris, Presses de Science Po, 2010, p. 51-71.

53 Voir notamment Antonin Cohen avec Yves Dezalay et Dominique Marchetti, «Esprits d'État, entrepreneurs d'Europe ", Actes de la recherche en sciences sociales, 166-167, mars 2007, p. 5-13. 
Faire un musée, ce n'est pas commettre un livre, c'est essentiellement un acte politique, surtout lorsqu'il s'agit d'un musée identitaire. ${ }^{54}$

Mieux vaut afficher hardiment nos intentions : nous voulons faire un musée identitaire. (...) Notre intention principale est de contribuer à la constitution de la conscience civique européenne (...). Ce n'est pas la pure curiosité scientifique qui nous motive, mais le souhait de participer à l'émergence d'un esprit civique européen. ${ }^{55}$

Musée d'histoire, le Musée de l'Europe est aussi un musée d'identité - comme le sont de nombreux autres musées au niveau local, régional ou national - pour contribuer à l'émergence d'un esprit civique européen. ${ }^{56}$

Ici, très clairement, plus que la vocation patrimoniale et scientifique de collecte, de conservation et de recherche inhérente au musée dans son sens classique, c'est l'inspiration identitaire qui motive prioritairement et qui justifie l'entreprise de production muséale. Mais c'est de manière tout à fait générale que les entrepreneurs des musées de l'Europe disent vouloir pallier les défaillances - pourtant constitutives - du processus de construction européenne en matière culturelle :

Pourquoi un Musée de l'Europe à Bruxelles ? [...] Parce que [...] il est grand temps que l'Europe se dote d'un outil culturel efficace. L'économie, c'est essentiel. Le marché unique, c'est parfait. La bureaucratie, c'est indispensable. Mais tout cela ne fabrique que des consommateurs et des administrés. Seules la culture et la conscience partagée d'une civilisation commune font des citoyens. ${ }^{57}$

Ce défi, celui de participer à la construction de "l'Europe de la culture ", ils le relèvent dans un double objectif: d'un côté, il s'agit de sortir l'Europe de la crise démocratique dans laquelle elle est plongée ; de l'autre, il s'agit de la rendre résistante face aux puissances mondiales concurrentes et en particulier à l'hégémonie américaine. Cela est dit sans détours :

L’objectif [initial du Musée de l'Europe] était de s'intéresser au développement de "l'esprit de l'Europe » et de consacrer un musée à la culture commune de l'Europe, pour donner un instrument culturel à l'Union européenne en train de se construire ; il s'agissait de lutter contre l'hégémonie exercée par les ÉtatsUnis sur l'industrie du spectacle (1999)..$^{8}$

54 Propos tenus par Benoît Remiche lors d'une journée d'études organisée, à Paris, sur le thème : "Une Europe sans histoire ? ", sous la présidence de Jean-Pierre Rioux, Inspecteur général du ministère de l'Éducation Nationale (8 mars 2001), cité dans Véronique Charléty, "Bruxelles, capitale européenne de la culture ? L'invention du Musée de l'Europe ? ", Politique européenne, 30 mars 2006 (p. 149).

55 Benoît Remiche, "Un musée d'histoire européenne à Bruxelles ", in Europa e Musei, op. cit., p. $129-132$ (p. 130).

56 Musée de l'Europe, «Le projet culturel », Cahier 4, Tempora, 2004, p. 6.

57 Benoît Remiche, op. cit., p. 129.

58 "L'esprit de l'Europe dans les musées ", Rapport de l'Assemblée parlementaire du Conseil de l'Europe, Doc. 9503, 15 juillet 2002. Rapporteur : M. Gerrit Valk, Pays-Bas, Groupe socialiste. 
Ce faisant, ces entrepreneurs marquent leurs distances vis-à-vis des politiques européennes et communautaires dont ils déplorent le trop timide investissement en la matière. C'est par exemple le cas des personnalités qui soutiennent le Musée de l'Europe (Bruxelles), Antoinette Spaak et Karel van Miert : « Notre association, fondée en 1997, a pour objet de créer un Musée de l'Europe pour doter Bruxelles et les institutions européennes d'un outil culturel qui leur fait cruellement défaut. " musei ", il était ainsi rappelé à regret que si les Traités de Maastricht et de Nice dotent l'UE de compétences nouvelles en matière culturelle, ils conservent à la culture sa place de pré-carré au national :

Nous avons dû construire le soubassement d'une identité européenne capable de mettre en valeur les différences autour d'un réseau de musées et de centres d'interprétation (...). Pourquoi devrait-il y avoir un réseau de musées de l'Europe ? Parce que l'Europe doit être construite au-delà de Maastricht et, plus encore, de Nice. La reconnaissance de la diversité des cultures européennes - qui se déclinent différemment mais sont reliées entre elles par la même syntaxe - doit être la clef de voute du projet européen pour l'identité et la culture. ${ }^{60}$

Les acteurs turinois qui estiment alors avoir un rôle à jouer dans la construction de l'unité européenne et entreprennent de se saisir du musée pour le montrer, mobilisent l'argument du déficit culturel de l'Union européenne pour pointer plus largement le risque encouru par l'Europe face à l'homogénéisation culturelle (standardisation) qui, en pleine globalisation galopante, la menacerait :

Sans la culture, nous risquons de construire une aire économique et de marchés protégés, quelque chose sans esprit. Nous ne devons pas cautionner cela. Au contraire, nous devons travailler ensemble pour retrouver nos racines historiques communes et pour comprendre comment les revisiter aujourd'hui dans une voie unifiée sans les standardiser. En fait, les variétés de la diversité culturelle représentent la grandeur de notre continent. ${ }^{61}$

Toutefois, il semble évident aux yeux de tous que la culture ne peut pas et ne doit pas être européanisée comme d'autres secteurs des politiques publiques. Cette conviction les incite à prôner la conciliation entre l'unité et la diversité. Tout en reprenant à leur compte la rhétorique de l'Union en matière culturelle, ils justifient ainsi la pluralité et la diversité des projets de musées de l'Europe, porteurs de visions multiples de la culture et du passé européen. Le Réseau des musées de l'Europe était censé en être le marqueur. L'historien

59 Élie Barnavi, Krzysztof Pomian et Benoît Remiche, La Belle Europe. Le temps des expositions universelles 1900-2000, Catalogue d'exposition, Musée de l'Europe, Musées Royaux d'Art et d'Histoire, Tempora, Bruxelles, 2001,

60 Valter Giuliano, op. cit., p. 19.

61 Idem, p. 19. 
Jacques Le Goff, dans son ouverture au colloque " Europa e musei », reprenait ainsi à son compte les concepts d'unité et de diversité, placés au cœur de la rhétorique communautaire :

Je voudrais réfléchir spécifiquement au projet de créer un ou plusieurs musées dédiés à l'Europe. Pourquoi pas juste un, mais plusieurs musées ? Parce que l'Europe est une, mais aussi diverse. C'est l'Europe unie qui est actuellement en cours de construction - avec quelques difficultés probablement. Cependant cela ne doit pas nous effrayer. Nous devons savoir comment préserver cette diversité dans son unité. ${ }^{62}$

Cela confirme l'idée selon laquelle aucun musée n'est jugé plus légitime qu'un autre pour imposer sa vision de la culture de l'Europe et proposer une interprétation de son passé, comme en atteste la création du Réseau des musées de l'Europe.

Le musée, perçu comme un outil démocratique et un medium incontournable du mécanisme d'identification au groupe et d'appropriation du sentiment d'appartenance est pressenti comme l'outil idéal pour rendre l'Europe insaisissable, froide et technocratique, plus accessible, plus chaude et plus tangible. Et de créer ainsi un "peuple européen ${ }^{63}$ dont la définition se confond avec celle de " citoyenneté européenne " :

On connaît le malaise qui s'est installé entre l'Europe et les citoyens. Beaucoup, aujourd'hui, s'en désintéressent ou ne voient en ses institutions que des structures technocratiques, froides, qui ne prennent jamais en compte les besoins réels des peuples. Le citoyen a du mal à s'identifier à l'Europe, et davantage encore à l'Union européenne. ${ }^{64}$

Il en va ainsi des musées de l'Europe, conçus comme des lieux d'éducation politique et comme des lieux d'apprentissage de la « citoyenneté européenne ». Le Musée de l'Union, qui fit l'objet d'une simple évocation en 1996 au sein de la Commission de Venise, s'inscrivait déjà dans le cadre de propositions concrètes en vue du renforcement de la " citoyenneté européenne" :

Eu égard à son impact grandissant sur la vie de tous les Européens, le processus de la construction européenne ne peut qu'être au centre de l'intérêt de la Commission européenne pour la Démocratie par le Droit. Celle-ci a donc décidé, encouragée par M. Jacques Santer, président de la Commission européenne, de transmettre à la Conférence intergouvernementale de 1996 une série de propositions sur la citoyenneté européenne. ${ }^{65}$

62 Jacques Le Goff, "Il medioevo nei musei d'Europa », in Europa e Musei, id., p. 39-44 (p. 39).

63 Sur les notions de "peuple européen " et de "citoyenneté européenne ", voir Klaus Eder, Bernhard Giesen (eds.), European Citizenship Between National Legacies and Post-national Projects, Oxford, Oxford University Press, 2001 ; Klaus Eder, "La construction d'un démos européen, Les sociétés transnationales peuvent-elles produire une identité collective ?", in L'Europe - un mythe politique ?, Identité européenne et citoyennetés nationales, publication de l'OFAJ, 2007.

64 Musée de l'Europe, «Le projet culturel », art. cit., p. 5.

65 Contribution de la Commission de Venise à la Conférence intergouvernementale de 1996, 
Fondé quant à lui en 1997, le Musée de l'Europe (Bruxelles) met " la citoyenneté européenne " au cœur de ses objectifs :

Il faut que nous nous mettions tous, autrement dit, à apprendre l'Europe en tant qu'entité à plusieurs dimensions, dotée d'une individualité propre, irréductible à l'ensemble des nations qui la composent. D'une telle éducation à la citoyenneté européenne, les musées de l'Europe ou de l'histoire nationale repensée dans le cadre de l'histoire de l'Europe peuvent devenir des instruments particulièrement efficaces. Pour notre part, en tout cas, nous aimerions y contribuer. ${ }^{66}$

À son tour, l'exposition permanente du Musée européen Schengen met en avant la notion de citoyenneté : "Citoyenneté, jumelages, mémoire - Justice, liberté, sécurité et immigration. Schengen : un village, des accords, un espace... et désormais un musée européen qui raconte l'histoire de l'ouverture des frontières. ${ }^{67}$ Et la Maison de l'histoire européenne se voit fixer à son tour, la mission de diffuser des messages de paix et de favoriser la participation accrue des citoyens au processus démocratique européen. Le futur établissement est annoncé comme l'outil nécessaire à la structuration et à la légitimation de l'Union comme communauté politique ${ }^{68}$, comme en atteste l'énoncé de ses principes fondateurs :

$\$ 5$. Lidée et la volonté de s’associer librement dans des institutions supranationales au niveau européen caractérise l'histoire récente du continent. Le rejet et le dépassement presque complet des nationalismes, de la dictature et de la guerre, ainsi que la volonté, apparue dans les années 1950, de vivre en paix et librement dans toute l'Europe, l'union supranationale à caractère civil, doivent être des messages prioritaires de la Maison de l'histoire européenne. Les expositions doivent montrer qu'une Europe unie par des valeurs communes peut vivre pacifiquement et librement dans un monde de progrès. La Maison de l'histoire européenne doit susciter une participation accrue des citoyens au processus décisionnel de l'Europe unie. ${ }^{69}$

En cela, les " musées de l'Europe " émergents qui sont, non sans difficulté, en cours d'institutionnalisation constituent une trace historique parmi d'autres de la tentative contemporaine de redéfinition de "l'identité " (passer des identités nationales à une identité et à une citoyenneté européennes), à travers la mobilisation des registres traditionnellement utilisés au national

CDL(1996)013f, Strasbourg, le 25 mars 1996.

66 Musée de l'Europe, "Introduction », Cahier 1, Tempora, 2004, p. 5.

67 Présentation du musée sur le site Internet Europaforum : http://www.europaforum.public.lu [dernière consultation le 02/08/2010].

68 Jacques Lagroye, «La légitimation », in Madeleine Grawitz et Jean Leca (éd.), Traité de science politique, t. 1, Paris, PUF, 1985, p. 399.

69 "Lignes directrices pour une Maison de l'Histoire européenne " (octobre 2008), Rapport du Comité d'experts, Maison de l'Histoire européenne, Bruxelles. 
du passé, de l'histoire et de la mémoire. Mais au-delà de ces déclarations de principe et de ces bonnes raisons déclarées d'agir, force est de constater qu'au projet initial, au rêve de départ, aux ambitions de passer des musées de la Nation à un nouveau modèle de musées capable de représenter, d'incarner et de diffuser le sentiment de "l'identité européenne ", ont succédé la désillusion et un certain désenchantement. Si certains enregistrent de francs succès en termes de fréquentation (Musée de l'Europe de Bruxelles notamment), les musées de l'Europe essuient, dans leur ensemble, un certain nombre d'échecs du point de vue de leur réalisation et de leur réception. Dès lors, il conviendrait ailleurs de procéder à une sociologie professionnelle du monde des musées de l'Europe et, surtout, au décryptage des mécanismes institutionnels et politiques qui font que les projets se font ou ne se font pas, sans pour autant sombrer dans un discours de l'échec et de la dénonciation ${ }^{70}$.

Camille Mazé

Université de Bretagne occidentale camille.maze@univ-brest.fr

\title{
Résumé
}

Les musées de société sont des institutions culturelles au croisement de la science et du politique. Ils constituent des traces historiques du rapport de nos sociétés à "l'identité ", au passé (histoire/mémoire) et au territoire, comme en atteste le cas contemporain du passage des musées de la Nation aux musées de l'Europe, que cet article se propose d'appréhender comme un sismographe de la redéfinition de ces rapports.

\section{Mots-clés}

Culture, science, politique, musée, identité.

\begin{abstract}
Society's museums are cultural institutions at the intersection between science and politics. They are like historical traces of the relationships between society and "identity", the past (history/memory) and territory. This article, dedicated to the contemporary case of the passage of national museums to European museums, seeks to understand these museums as a seismograph of the redefinition of these relationships.
\end{abstract}

\section{Keywords}

Culture, science, politicy, identity.

70 Voir Camille Mazé, La fabrique de l'identité européenne, op. cit. 